verdaderamente convincente, Alexandre Hay nunca renunció a sus principios y libró, con discernimiento y coraje, un combate incesante en pro de una mayor humanidad.

El 30 de agosto, se celebró en la Catedral de San Pedro, en Ginebra, un servicio conmemorativo al que asistió gran número de personas, entre ellas miembros de la Asamblea y del Consejo Ejecutivo del CICR, muchos de sus colaboradores, representantes de Sociedades Nacionales de la Cruz Roja y de la Media Luna Roja y de su Federación, la Liga, así como representantes de las autoridades federales y cantonales. Su sucesor en la Presidencia, el señor Cornelio Sommaruga, rindió un conmovedor homenaje al presidente fallecido, que la Revista desea compartir con sus lectores.

La Revista

\title{
Homenaje al señor Alexandre Hay
}

Desde hacía varios meses, Alexandre Hay resistía serenamente, con valor y lucidez, los repetidos ataques de un mal cuya gravedad sospechaba. Su confianza en sus médicos era inquebrantable; pero, hombre de una fe profunda, sabia que, aunque el deber de cada individuo es hacer todo lo posible por garantizar el éxito de sus empresas, la última palabra la tiene el Señor del universo. Nunca ostentó sus convicciones religiosas, pero en la hora de su última gran decisión, no tuvo ningún reparo en afirmar, con toda sencillez, su total sumisión a la voluntad de Dios.

Hasta el 23 de agosto, compartimos con él y su familia su confianza. Pero la situación no evolucionó en el sentido de nuestros deseos y la realidad se nos impuso, poniendo fin a todas nuestras esperanzas. Profundamente conmovidos, los miembros y colaboradores del CICR, todos los amigos de la Cruz Roja y de la Media Luna Roja, compartimos el dolor de sus familiares y allegados, especialmente el de la señora Hay quien, desde los primeros embates de la enfermedad, le confortó con su infatigable solicitud.

Los días transcurridos desde esta primera e intensa emoción nos han permitido evaluar la pérdida que acabamos de sufrir. La voz de Alexandre Hay se ha callado y ya no contamos con su cálida y acogedora personalidad. Pero, poco a poco, el dolor da paso a la reflexión, 
y nuestro pensamiento se fija en la trayectoria de quien acaba de partir, en todo lo que nos dio, todo lo que aportó a la Cruz Roja, todo lo que hizo para aliviar los sufrimientos de tantas víctimas de los conflictos.

Volvemos a ver, asi, hechos que conocíamos, pero que percibimos hoy con renovada admiración. ¿Cómo pudo este hombre cuyas tendencias artísticas eran prometedoras, sin sacrificar sus gustos ni sus convicciones intimas, pasar con tanta facilidad de la abogacía a la diplomacia, de la diplomacia a las finanzas, de las finanzas a la acción humanitaria, campos de acción que pueden parecer tan alejados entre sí, y encontrar en la misión de la Cruz Roja su realización y los mejores logros de su vocación?

Sería absurdo decir que tenía su "secreto», puesto que, aunque la discreción era un rasgo de su carácter. Alexandre Hay no tenía la manía del secreto ni cultivaba el misterio. Al evocar hoy complacidos que era un hombre querido y apreciado, notamos también una característica constante: dondequiera que actuara, era sumamente consciente de que todos los que lo rodeaban, tanto dentro como fuera de la Institución, arriba y abajo en la escala jerárquica, eran sus iguales, que él era tan sólo uno de ellos y que todos, en puestos diferentes, tienen por misión unir sus esfuerzos para servir al prójimo. Poseía, como don innato, el espíritu de servicio, fundado en el respeto de la persona, inspirado a su vez en un sentido agudo de la justicia y en una caridad discreta y profunda.

En el desempeño de las altas funciones que asumió, su conciencia de dirigente estaba asociada a la intima convicción de que era, ante todo, un servidor, un hombre al servicio de todos. Su primera inquietud era, pues, escuchar a los demás, como si el «conocer mejor» fuera el requisito indispensable para «servir mejor». Rara vez se manifestaba antes de haber escuchado y cuando lo hacía, era con calma y sencillez, sin buscar adornar sus frases. Su tono era cordial y sus palabras eran convincentes. Todos sabiamos que sus opiniones eran fruto de una sana reflexión. Su arte para conducir a los hombres era, además, particular y eficaz: su autoridad natural se imponía.

Discreción, espiritu de servicio, respeto por todo interlocutor, voluntad de servir a todos, lenguaje sencillo y concreto: cualidades todas que hacían de él un perfecto «hombre de Cruz Roja». Los Principios Fundamentales de humanidad, independencia, neutralidad $e$ imparcialidad estaban siempre presentes en sus discursos. Eran para él un criterio de comportamiento personal cotidiano. Cuando llegó al CICR, procedente de Berna, demostró rápidamente su capacidad de adaptación a la misión humanitaria, preservando la independencia 
necesaria, que tan bien habia practicado en el Banco Nacional Suizo. La negociación humanitaria le interesaba; sabía captar la atención y granjearse la confianza de sus interlocutores al más alto nivel tanto de los Estados como de las organizaciones internacionales o los grupos de oposición más diversos. "Suaviter in modo, fortiter in re" hubiera podido ser su divisa.

Más allá de las consideraciones jurídicas, diplomáticas o políticas, su reflexión no perdía nunca de vista esta última finalidad que nos transmitieron los fundadores de la Cruz Roja: la humanidad. Y, cuando uno de sus colegas o colaboradores, en el fragor de la acción. olvidaba la humanidad al servicio de la cual estaba, el ex presidente sabía ponerlo, con firmeza y una sonrisa, nuevamente en el buen camino. A pesar de verse confrontado diariamente con la miseria, la desesperación y la crueldad, Alexandre Hay, inspirado en su profunda convicción humanista y humanitaria, irradiaba una fuerza serena y un optimismo, que transmitía con total naturalidad a todos cuantos lo rodeaban.

Muchas fueron las puertas que se abrieron al CICR gracias a la negociación humanitaria de Alexandre Hay: su constante preocupación era llegar a todas las víctimas de los conflictos, a todos los que tenían derecho a la protección y la asistencia de los delegados del CICR. Pero la negociación incluía también los aspectos financieros. $\mathrm{Su}$ talento de economista y organizador, sus relaciones personales y muchos años de diplomacia económica y monetaria lo habian capacitado para ello. Su riguroso desvelo por la Institución, pero también su alma caritativa y su capacidad de convencimiento lo llevaron a defender con ahínco las necesidades financieras del CICR ante los Estados y las Sociedades Nacionales, así como ante múltiples organizaciones y donantes privados. Los buenos resultados de esa gestión permitieron a la Institución hacer frente a la expansión de sus operaciones, en un mundo donde cada día era más necesaria la acción de un intermediario neutral: el Comité Internacional de la Cruz Roja.

El desarrollo, la difusión y la aplicación del derecho internacional humanitario eran para Alexandre Hay preocupaciones prioritarias. Habia que impedir que el crecimiento operacional del CICR relegara $a$ un segundo plano las responsabilidades históricas, morales y convencionales de la Institución en materia de derecho. Fue sobre todo en ese ámbito, así como en el de la financiación, donde mantuvo relaciones transparentes y de confianza mutua con el Consejo Federal, el Parlamento y la Administración suizos. Dado que, en aquel entonces, yo estaba en Berna, pude comprobar personalmente la gran estima que inspiraba en el Palacio Federal, donde se conocia perfec- 
tamente su coraje frente a los grandes desafios humanitarios de nuestro tiempo.

Tanto en sus conferencias como en sus discursos, introducia siempre un llamamiento en favor de una movilización humanitaria sobre la base de los principios de la Cruz Roja. El «Espíritu de Ginebra» impregnaba constantemente la acción de este ginebrino, orgulloso de hallarse al frente de esta magnifica obra que Ginebra ha ofrecido al mundo.

El Movimiento Internacional de la Cruz Roja y de la Media Luna Roja, su cohesión, su unidad, fueron inquietudes permanentes de Alexandre Hay hasta los últimos momentos de su vida. Buscaba constantemente el diálogo con los protagonistas de la acción humanitaria tanto en la Liga como en las Sociedades Nacionales. Le preocupaban ciertas dificultades de comunicación, temía la politización del mundo de la Cruz Roja, insistía en que, en el proceso de evolución dinámica del Movimiento, el CICR debe preservar su papel de institución específicamente neutral con un cometido particular, cuya realización requiere el apoyo y la participación de las Sociedades Nacionales. La firmeza de sus posiciones en favor de la cohesión del Movimiento, la defensa de los Principios Fundamentales, el interés que demostraba por el desarrollo de las Sociedades de la Cruz Roja y de la Media Luna Roja - a las que en su gran mayoría había visitadosu compromiso en favor del voluntariado, su sensibilidad con respecto a las cuestiones femeninas dentro de las organizaciones de la Cruz Roja le valieron un gran respeto y sentimientos de admiración - con gran frecuencia de amistad - en todos los medios del Movimiento.

Prueba de ello es hoy la participación en este acto de tantas personalidades del mundo de la Cruz Roja. Los mensajes que nos llegan de colegas y amigos de la Cruz Roja y de la Media Luna Roja del mundo entero ponen de relieve que la infatigable labor humanitaria de nuestro ex presidente en el marco del CICR constituye no sólo un notable ejemplo, sino también y sobre todo una enseñanza perdurable al servicio de los más nobles objetivos de paz y de justicia, por los cuales nunca dejó de luchar con ardor, sabiduría y eficacia.

Fiel al lema "per humanitatem ad pacem», fue precisamente en el ámbito de la búsqueda de la Paz donde centró sus esfuerzos tras la finalización de su cargo como presidente del CICR. Cuando lo sucedí, en mayo de 1987, dijo en su discurso ante la Asamblea que quería centrar los trabajos de la Comisión sobre la Cruz Roja, la Media Luna Roja y la Paz, cuya presidencia acababa de asumir, en «la acción que es necesario desplegar entre los jóvenes y en las cuestiones relativas a la información: ¿cómo hacer comprender mejor en 
todo el mundo la contribución de la Cruz Roja a la Paz?", se preguntaba. Era, pues, totalmente lógico que participara en la Campaña Mundial para la Protección de las Víctimas de la Guerra, su último esfuerzo concreto y público en el marco de la Cruz Roja. El 8 de mayo, asistió al concierto en la Avenida de la Paz, a pesar de que su salud estaba ya muy quebrantada, para presenciar el punto culminante de la Campaña.

Alexandre Hay fue un hombre de acción, guiado por una gran sensibilidad y una inmensa ternura. No pretendió dar lecciones a nadie. Pero con su obra y su vida nos ha dado un maravilloso testimonio de lo que puede hacer un hombre de corazón, valiente y capaz de inspirar confianza, que no se aparte jamás de un ideal de amor al prójimo. Cuando un hombre con tal carisma deja este mundo, cualquiera que sea su edad, es siempre demasiado pronto.

El duelo de su esposa y de su familia es el de todos los que conocieron a Alexandre Hay y de todos los que aspiran a una mayor justicia y a un mayor respeto de los derechos humanos. El Movimiento de la Cruz Roja y de la Media Luna Roja en su conjunto, y más particularmente el CICR, todos sus miembros, sus colaboradoras y colaboradores, los de hoy y los de ayer, yo mismo - beneficiario de su gran apoyo y de su precioso asesoramiento al sucederlo en el cargo -, le debemos todos una inmensa gratitud.

Ginebra y Suiza, toda la comunidad internacional, las víctimas del mundo entero se asocian a este sentimiento de gratitud y admiración por un gran servidor de la humanidad. Su extraordinaria personalidad permanecerá siempre en nuestra memoria.

\section{Cornelio Sommaruga \\ Presidente \\ Comité Internacional \\ de la Cruz Roja}

